\title{
Intermittent hypoxia and sleep-disordered breathing: current concepts and
} perspectives

\author{
P. Lévy*,", J-L. Pépin*,\#, C. Arnaud*, R. Tamisier*\#, J-C. Borel*\#,", M. Dematteis**, \\ D. Godin-Ribuot* and C. Ribuot*
}

ABSTRACT: There are three major types of sleep-disordered breathing (SDB) with respect to prevalence and health consequences, i.e. obstructive sleep apnoea syndrome (OSAS), CheyneStokes respiration and central sleep apnoea (CSR-CSA) in chronic heart failure, and obesity hypoventilation syndrome (OHS). In all three conditions, hypoxia appears to affect body functioning in different ways. Most of the molecular and cellular mechanisms that occur in response to SDB-related hypoxia remain unknown.

In OSAS, an inflammatory cascade mainly dependent upon intermittent hypoxia has been described. There is a strong interaction between haemodynamic and inflammatory changes in promoting vascular remodelling. Moreover, during OSAS, most organ, tissue or functional impairment is related to the severity of nocturnal hypoxia. CSR-CSA occurring during heart failure is primarily a consequence of cardiac impairment. CSR-CSA has deleterious consequences for cardiac prognosis and mortality since it favours sympathetic activation, ventricular ectopy and atrial fibrillation. Although correction of CSR-CSA seems to be critical, there is a need to establish therapy guidelines in large randomised controlled trials.

Finally, OHS is a growing health concern, owing to the worldwide obesity epidemic and OHS morbidities. The pathophysiology of OHS remains largely unknown. However, resistance to leptin, obesity and severe nocturnal hypoxia lead to insulin resistance and endothelial dysfunction. In addition, several adipokines may be triggered by hypoxia and explain, at least in part, OHS morbidity and mortality.

Overall, chronic intermittent hypoxia appears to have specific genomic effects that differ notably from continuous hypoxia. Further research is required to fully elucidate the molecular and cellular mechanisms.

KEYWORDS: Atherosclerosis, Cheyne-Stokes respiration, inflammation, intermittent hypoxia, obesity hypoventilation syndrome, sleep apnoea

leep-disordered breathing (SDB) represents a growing health concern. Sleep apnoea has been known for centuries and was rediscovered at the beginning of the 20th century. In the late 1990s, however, different types of SDB have been recognised, with specific consequences and morbidities. At the end of the 1990s, a revised classification was suggested by the American Academy of Sleep Medicine [1] and further confirmed through the International Classification of Sleep Disorders, second edition (ICDS-2) [2], published in 2005. There are three major SDB types with respect to prevalence and health consequences, i.e. obstructive sleep apnoea

\section{AFFILIATIONS}

*INSERM ERI17, Hypoxia

PathoPhysiology laboratory, Grenoble

University, and

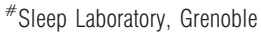

University Hospital, Grenoble, and

•AGIRàdom, Meylan, France.

CORRESPONDENCE

P. Lévy

EFCR

Pôle Rééducation et Physiologie

CHU Grenoble

38043 Cedex 9

France

Fax: 33476765586

E-mail: PLevy@chu-grenoble.fr

Received:

January 282008

Accepted after revision:

January 312008

SUPPORT STATEMENT

This study was supported by grants from Direction de la Recherche Clinique 2005 and Programme Hospitalier de Recherche Clinique regional 2006, CHU Grenoble, France.

STATEMENT OF INTEREST None declared. 
(OSA) syndrome (OSAS), Cheyne-Stokes respiration (CSR) and central sleep apnoea (CSA) in chronic heart failure (CHF), and obesity hypoventilation syndrome (OHS). Figure 1 shows the type of respiratory events occurring in all three conditions, as reflected by oxygen saturation and ventilatory changes during 5-min recordings.

In all three conditions, hypoxia appears to affect body functioning in different ways, with specific mechanisms. Moreover, experimental models have been developed that permit a better understanding of the molecular and cellular mechanisms in response to SBD-related hypoxia. The present paper covers all of these specific issues.

\section{OBSTRUCTIVE SLEEP APNOEA SYNDROME Definition, prevalence and main consequences}

OSAS is defined by symptoms such as excessive daytime sleepiness (EDS) and daytime functioning impairment, with $>5$ obstructive events $\cdot \mathrm{h}^{-1}$ occurring during sleep. The scoring of ventilatory events includes apnoeas, hypopnoeas and also episodes of increased upper airway resistance. Both the ICSD-2 [2] and American Academy of Sleep Medicine [1] guidelines recommend that this latter type of event should be included in OSAS, since the specificity of upper airway resistance syndrome [3] has not been considered, until now, to be supported by sufficient epidemiological, pathophysiological and clinical data.

The prevalence of the disease is very high, ranging $5-15 \%$, increasing linearly up to the age of $60 \mathrm{yrs}$ and becoming more variable above this threshold age, at least regarding obstructive events [4]. Regarding OSAS morbidity [5], there is now substantial evidence that there is a causal relationship between OSA and EDS, with cognitive impairment, including increased risk of traffic accidents [6,7], and cardiovascular morbidity and mortality [7-9]. The cardiovascular consequences, e.g. occurrence of atherosclerosis without significant classical cardiovascular risks in OSA, seem to appear early in the disease $[10,11]$. This supports the need for early diagnosis and treatment, especially since the mortality rate is maximal in males aged $<50$ yrs and thereafter declines with age [12]

\section{Intermittent hypoxia, a major stimulus}

The desaturation-reoxygenation sequence is a typical pattern coupled with the majority of respiratory events. This sequence, defining intermittent hypoxia (IH), leads to oxidative stress, with production of reactive oxygen species (ROS) [13]. Numerous studies have shown increased oxidative stress using various biological markers, although comorbid conditions such as diabetes, hypertension and obesity may account for some of these results [13-16]. The increased levels of ROS contribute to the generation of adhesion molecules [17], activation of leukocytes [18] and production of systemic inflammation [19]. Together, these mechanisms generate vascular endothelial damage and dysfunction [20, 21]. Moreover, high sympathetic output, as consistently found in OSA, may lead to insulin resistance, even in nonobese OSA patients [22], representing an additional source of oxidative stress. Oxidative stress is characterised by an imbalance between the production and degradation of ROS. Although numerous studies have addressed the issue of increased ROS production, there are only a limited number of studies
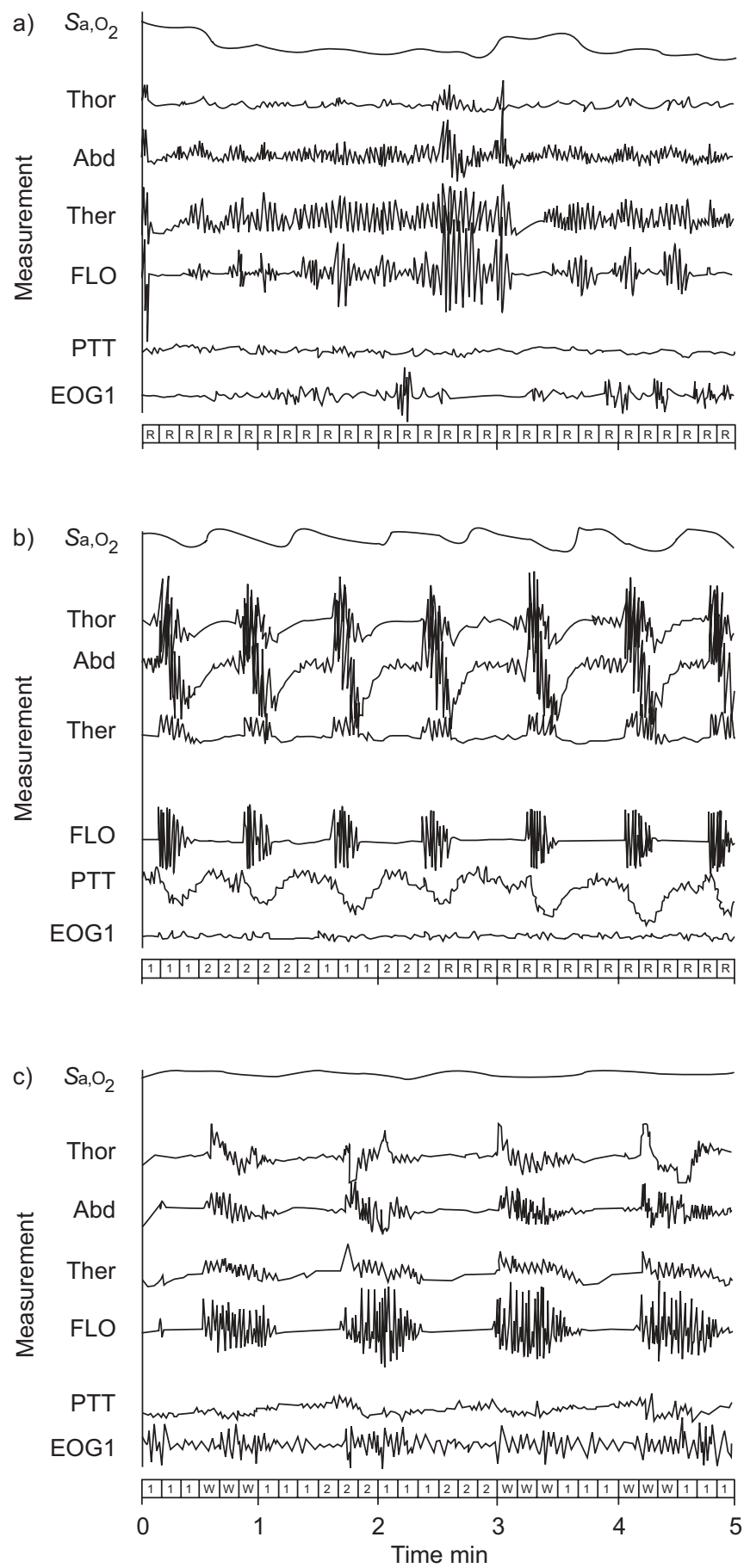

FIGURE 1. Polysomnographic comparison of three characteristic ventilatory patterns in the three major types of sleep-disordered breathing: a) rapid eye movement sleep hypoventilation in obesity hypoventilation syndrome, b) obstructive sleep apnoea syndrome, and c) periodic breathing during Cheyne-Stokes respiration in congestive heart failure (5-min epochs). Sleep stage is indicated on the $x$-axis: $\mathrm{R}$ : rapid eye movement; 1 : stage $1 ; 2$ : stage 2 ; $\mathrm{W}$ : wakefulness. $\mathrm{Sa}_{\mathrm{O}_{2}}$ : arterial oxygen saturation; Thor: thoracic movements; Abd: abdominal movements; Ther: oronasal thermistor (to assess persistent nose or mouth breathing by temperature measurement); FLO: nasal pressure; PTT: pulse transit time; EOG: electro-oculogram. 
addressing the role of antioxidant capacities in OSA patients. BARCELO et al. [23] reported an alteration in antioxidant capacities, with a reduction in total antioxidant status, and a decrease in both vitamin A and E levels. In the same study, continuous positive airway pressure (CPAP) treatment normalised total antioxidant status [23]. In 2008, impairment of albumin antioxidant properties independent of body mass index (BMI) and related only to OSA severity has been demonstrated [24].

OSA has also been shown to be associated with a reduction in nitric oxide bioavailability. Nitric oxide derivatives include the nitrosonium ion $\left(\mathrm{NO}^{+}\right)$, which results from the auto-oxidation of nitric oxide under certain conditions, and peroxynitrite $\left(\mathrm{ONOO}^{-}\right)$, which is the product of the reaction between nitric oxide and the superoxide ion $\left(\mathrm{O}_{2}{ }^{-}\right)$, since peroxynitrite is generated in situations associated with increased oxidative stress, e.g. hypoxia and ischaemia-reperfusion, particularly at the level of the vascular wall. Peroxynitrite has been shown to modulate the activity of several key enzymes of vascular homeostasis, such as endothelial nitric oxide synthase, Akt kinase and catalase. By inhibiting endothelial nitric oxide synthase activity through AMP kinase [25] and catalase [26], peroxynitrite favours the generation of superoxide ions, thus inducing a vicious cycle leading to increasing local oxidative stress with deleterious consequences. In OSA, a reduction in nitric oxide availability has been demonstrated, as well as an increase in levels of its derivatives [27, 28], although this has not always been confirmed [29]. It is viewed as being an important determinant of the endothelial dysfunction associated with OSA [13].

Oxidative stress generates an inflammatory cascade via nuclear factor- $\kappa \mathrm{B}(\mathrm{NF}-\kappa \mathrm{B})$ activation [30]. However, there is still much discussion regarding the confounding influence of obesity and the associated cardiovascular morbidity on the relationship between sleep apnoea severity and inflammatory markers. This is presumably responsible for the conflicting results obtained regarding C-reactive protein in OSA. Although Creactive protein levels were found to be elevated in several studies [31-33], other reports failed to demonstrate any linear relationship with the severity of OSA [34].

The inflammatory cascade increases adhesion molecule expression [35] and further activates monocytes and lymphocytes [36, 37]. In 2007, it was shown that impairment of endothelium-dependent vasodilation correlated with the degree of endothelial cell apoptosis. Also, CPAP therapy led to a significant decline in circulating apoptotic endothelial cell numbers [38]. All of these mechanisms lead to endothelial dysfunction and damage. Moreover, $\mathrm{IH}$ is associated with significant cyclical haemodynamic changes that may also contribute to endothelial dysfunction.

\section{Cellular and molecular consequences of IH}

There is now substantial evidence that $\mathrm{IH}$ and continuous hypoxia $(\mathrm{CH})$ lead to differential gene activation. Studies on cell cultures have revealed that $\mathrm{IH}$ is a more potent stimulus for transcriptional activation than $\mathrm{CH}$ at a comparable level of hypoxia intensity and duration. Hypoxia-inducible factor 1 has been shown to be more activated during $\mathrm{CH}$ than during $\mathrm{IH}$ in some [39] but not all studies [30]. Indeed, several experimental factors may be critical to explaining these discrepancies, i.e. cellular type, and intensity and duration of the hypoxic stimulus. As a consequence, downstream end-products such as erythropoietin and vascular endothelial growth factor on the one hand, and tumour necrosis factor (TNF)- $\alpha$ and other proinflammatory cytokines on the other, have been shown to be differently affected [30, 40-42].

$\mathrm{IH}$ has been studied in various models. Cellular models of $\mathrm{IH}$ are still poorly developed. There is major difficulty in establishing such models since changing intracellular oxygen content implies rapid modification of the oxygen fraction in the media surrounding the cells. Thus it remains difficult to obtain rapid cyclical intracellular oxygen content changes, whatever the cellular type [43], owing to gas exchange inertia in the media. Some models are also essentially acute and far from chronic IH $(\mathrm{CIH})$ as seen in OSA [30], whereas others seem to be more realistic [44]. This has permitted the demonstration of selective activation of NF- $\mathrm{B}$ [30], ROS production and mitochondrial dysfunction [44]. Increased dopamine secretion also occurs via $\mathrm{IH}$ induction of tyrosine hydroxylase $(\mathrm{TH})$ phosphorylation in rat pheochromocytoma 12 cells. $\mathrm{TH}$ is the rate-limiting enzyme that catalyses the conversion of tyrosine into dihydroxyphenylalanine in catecholamine biosynthesis. This $\mathrm{TH}$ activation has been shown to involve increased serine phosphorylation without augmenting $\mathrm{TH}$ protein expression, in contrast with chronic $\mathrm{CH}$ [45]. This represents one of the differential cellular changes expressed in response to IH.

There have been great advances in animal models since the early 1990s. One major advance, although the experiments were difficult to perform on a long-term basis, was the canine model, in which upper airway obstruction and sleep fragmentation were compared in terms of the acute and chronic cardiovascular consequences [46-48]. However, much more research in the field of hypoxia has been performed using wild-type or genetically modified rodents [49]. This is also true regarding $\mathrm{IH}$ [50]. Starting with the early evidence provided by FLETCHER et al. [51] that night-time CIH results in permanent daytime hypertension, there have been many reports on $\mathrm{IH}$ effects, mainly on the cardiovascular system. Vascular reactivity has been shown to be altered in various fashions in rodents [52-55]. A variety of biological and pathophysiological changes have also been demonstrated, i.e. altered baroreflex activity [56], increased pulmonary arterial pressure and haematocrit [57], changes in heart structure and function [58], altered endothelium-dependent vasodilation in cerebral and muscular arteries [59], and an increased response to endothelin (ET)-1 [54], presumably mediated almost exclusively by ETA receptors [60]. During IH, both blood pressure (BP) and myocardial changes might be critically dependent upon ET-1. Evidence has recently been found for an increase in ETA receptor expression and large ET-1 concentration at the level of the heart in spontaneously hypertensive rats submitted to $\mathrm{IH}(\mathrm{E}$ Belaïdi, Hypoxia PathoPhysiology laboratory, Grenoble University, Grenoble, France; personal communication). This was associated with aggravation of both the IH-related increase in BP, in contrast with a previous report [58], and increased infarct size during ischaemia, both being suppressed by ET-1 receptor antagonists (E Belaïdi; personal communication). There is also altered sensitivity to ischaemia, which is reduced when $\mathrm{IH}$ is acute, acting as a pre-conditioning 
stimulus [61], and increased when chronic [62]. Overall, these results support further therapeutic perspectives regarding cardiovascular modulation in OSA patients. In this context, ET-1 receptors might represent an adequate pharmacological target requiring further testing.

More recently, metabolic and atherosclerotic changes have been shown in mice exposed to $\mathrm{CIH}[63,64]$. At the arterial level, significant systemic inflammation occurs, as evidenced by $\mathrm{T}$-cell activation characterised by spleen-derived $\mathrm{T}$-cell proliferation and chemokine mRNA expression. In the present authors' experience, this occurs from day 5 of IH. In mesenteric resistance arteries, intercellular adhesion molecule- 1 expression increased at day 14 of $\mathrm{IH}$ and was associated with increased leukocyte rolling. Aorta from hypoxic mice exhibited both activation of the pro-inflammatory transcription factor NF- $\kappa \mathrm{B}$ and increased intima-media thickness at 14 days. Thus there was both systemic and localised inflammation of small and large arteries due to $\mathrm{IH}$. Moreover, there was recovery of lymphocyte proliferation, chemokine expression and NF- $\kappa B$ activation after oxygen fraction normalisation for several days (data not shown). In another study, there was also a reduction in levels of platelet-endothelial cell adhesion molecule-1, a marker of the endothelial cell, at both the heart and aorta level, with a specific gradient and without loss of endothelial cells, suggesting a role of shear forces applied to both the heart and the aorta [65]. Thus, in both studies, there was vascular remodelling resulting from either haemodynamic or inflammatory changes. From these two studies and other previously published studies [30,64, 66-68], it can be suggested that there are strong interactions in response to $\mathrm{CIH}$ between haemodynamic alterations, systemic inflammation and metabolic changes, modulated by the genetic background (fig. 2).

Other noncardiovascular changes related to $\mathrm{IH}$ have also been reported, including serotonin-dependent neuronal plasticity in the central control of breathing [69], long-term facilitation of diaphragmatic [70] and genioglossus muscle activity [71], and improved diaphragmatic anoxic tolerance [72]. Sensory longterm facilitation occurs at the level of the carotid body during $\mathrm{CIH}$ but not during $\mathrm{CH}$ of the same magnitude, suggesting that enzymatic changes at the carotid body level are related to ROS production. This effect is abolished on pre-treatment with a superoxide anion scavenger. Thus, this appears to be ROSdependent reversible functional plasticity of carotid body sensory activity [73]. There are also brain adaptations and damage that have been described. These include behavioural and brain anatomical and functional changes, also partly specifically related to oxidative stress [74, 75]. IH increases levels of protein oxidation, lipid peroxidation and nucleic acid oxidation in mouse brain cortex, promoting cell apoptosis [76]. It also promotes the reduced nicotinamide adenine dinucleotide phosphate oxidase gene and protein responses in wakeactive brain regions, a possible mechanism of sleepiness [77]. In rat hippocampal slice preparations, a reduction in the ability of neuronal tissue to express and sustain long-term potentiation has also been shown. Long-term potentiation correlated with biphasic changes in cyclic AMP-response elementbinding protein phosphorylation and programmed cell death [78]. There were also specific proteic changes at this level, with various susceptibilities to $\mathrm{IH}$. Hypoxia-regulated proteins in the cornu ammonis 1 region of the hippocampus included structural proteins, proteins related to apoptosis, primarily chaperone proteins, and proteins involved in cellular metabolic pathways [79]. These functional and structural changes may contribute to the $\mathrm{IH}$-induced changes in cognitive function in rodents, and may also alter neurogenesis [80]. It may explain part of the cognitive dysfunction in apnoeic patients. Cognitive changes occurring in sleep apnoea patients [81-83] may be linked to anatomical and functional changes occurring at the level of the brain, specifically at the pre-frontal cortex [84] and hippocampal levels $[85,86]$.

\section{IH-related tissular and functional impairment in OSA}

Although there is no ideal animal model in OSA, IH has been established as a successful model since it reproduces many of the cognitive, cardiovascular and metabolic alterations seen in OSA. One very complementary approach is to look at sleep apnoea consequences and determine whether or not hypoxia is a major determinant thereof. One way to do so is to determine predictive or explanatory factors using logistic regression analysis. Reversing symptoms and various impairments with CPAP application, the first-line treatment in OSA, does not provide direct evidence of an $\mathrm{IH}$ contribution, since it also suppresses sleep fragmentation, changes in plasmatic carbon dioxide content and intrathoracic pressure fluctuations. However, most, if not all, sleep apnoea consequences are related to $\mathrm{IH}$ severity. This may be illustrated by the three following different examples in various organs and systems.

\section{Peripheral nerve}

Peripheral nerve is very sensitive to changes in nutrient and oxygen content. This has been strongly evidenced previously in diabetes and chronic respiratory failure. Assessment of the peripheral nerve in OSA has been made using the usual clinical and neurophysiological indices [86]. There were multiple peripheral nerve anomalies in OSA patients compared to controls. Median pre-ischaemic sensory and mixed nerve potential amplitudes and sensory conduction velocities were lower in OSA patients than in control subjects despite higher supramaximal stimulation. Interestingly, the most severe OSA patients exhibited a very specific pattern of conduction during ischaemia. During ischaemia, OSA patients with the most severe nocturnal oxygen desaturation manifested resistance to ischaemic conduction failure (RICF), whereas both OSA patients with limited oxygen desaturation and controls did not show RICF. Under CPAP, RICF disappeared in all OSA-RICF patients. Oxygen saturation was the critical factor since CPAP suppressed RICF without any change in BMI [87]. This is presumably an adaptive mechanism to the severity of hypoxia, whereas axonal defects that persisted after treatment may instead represent hypoxic lesions.

\section{Blood pressure}

It is now well established and recognised in international guidelines that hypertension can be caused by OSA [88, 89]. However, nonapnoeic respiratory events generating no or very little oxygen desaturation, such as upper airway resistance syndrome, although generating increased nocturnal sympathetic activity, may not be associated with daytime hypertension. Conversely, upper airway resistance syndrome seems to be associated with hypotension in $\sim 20 \%$ [90]. This underlines the role of hypoxia in promoting hypertension, as also 


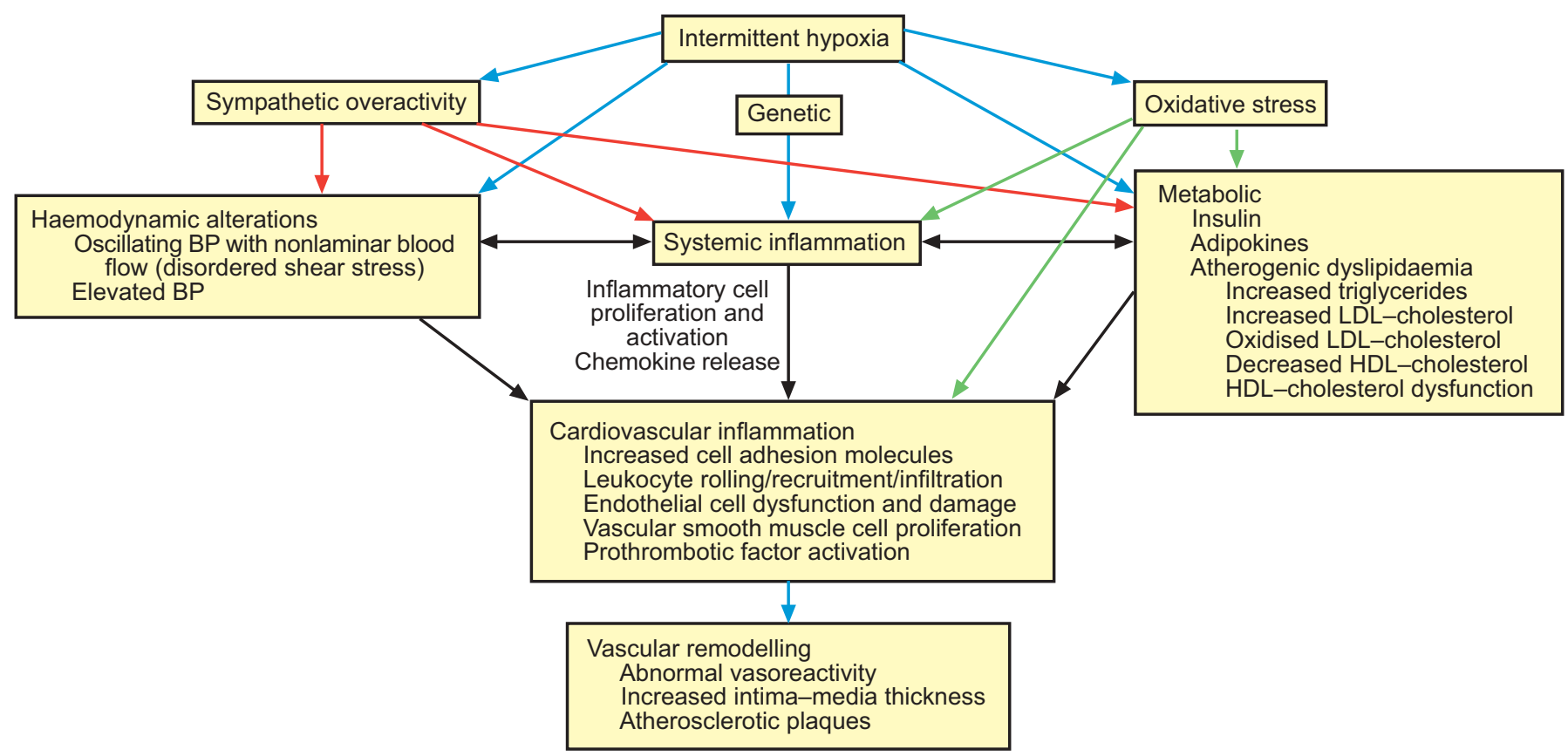

FIGURE 2. Intermittent hypoxia leads to sympathetic overactivity, oxidative stress, systemic inflammation and metabolic changes. There is a very complex interaction between all of these factors in promoting vascular impairment and remodelling during intermittent hypoxia. Red arrows denote the overall impact of sympathetic overactivity, blue arrows denote intermittent hypoxia and green arrows denote oxidative stress. BP: blood pressure; LDL: low-density lipoprotein; HDL: high-density lipoprotein.

evidenced in animal models [48]. The response to CPAP also indicates that a significant reduction in BP may mainly be seen in the most severe patients [9,91]. In 2007, this was evidenced in a meta-regression analysis showing a significant increase in the effect size of CPAP on BP with apnoea/hypopnoea index (AHI) and duration of CPAP use but not with EDS [92], although this latter point remains the subject of discussion [93, 94]. Thus the contribution of IH may be critical, even though severe OSA patients also present with marked sleep fragmentation and respiratory efforts.

\section{Atherosclerosis}

There have been significant efforts in this field of clinical research in reducing the number of confounding factors and comorbid conditions. In 2005, three reports were published almost simultaneously evidencing that sleep apnoea may lead to early atherosclerosis, as reflected at the carotid level by an increase in intima-media thickness and occurrence of plaques, in the absence of any significant comorbidity [10, 11, 95]. In the present series of patients, severity of oxygen desaturation and BP status were the best predictors of carotid wall hypertrophy. Plaque occurrence in this group of OSA patients without known cardiovascular disease was also strictly related to the amount of oxygen desaturation [11]. Interestingly enough, in 2007, DRAGER et al. [96] published data showing that CPAP treatment reverses early signs of atherosclerosis.

\section{Confounding factors}

There are clearly confounding factors when investigating the relationship between sleep apnoea, $\mathrm{IH}$ and their cardiovascular or metabolic consequences. The most important factor is obesity since $\sim 50 \%$ of apnoeic patients present with significant overweight. Moreover, obesity, and specifically visceral obesity, correlates closely with OSA prevalence. Finally, most biological parameters, such as inflammatory and oxidative stress markers and most clinical or subclinical metabolic and cardiovascular changes, can be, at least partly, explained by the presence of concomitant visceral obesity. It should also be mentioned that there is a synergistic effect of obesity and sleep apnoea on both metabolic and cardiovascular morbidity [34, 42, 97-99]. Regarding metabolic changes induced by OSA, CPAP has been suggested as improving insulin sensitivity [100]. However, the effects of CPAP on insulin sensitivity were smaller in obese patients than in nonobese patients, suggesting that, in obese individuals, insulin sensitivity is mainly determined by obesity [100]. There are also conflicting results from type 2 diabetic patients concurrently having OSA. A recent well-designed randomised controlled trial comparing therapeutic $(n=20)$ or placebo CPAP $(n=22)$ for 3 months found no difference in terms of glycaemic control or insulin resistance in these patients [101]. Again, in obese males with metabolic syndrome, CoughLIN et al. [102], in a randomised placebo-controlled blinded crossover trial comparing cardiovascular and metabolic outcomes after 6 weeks of therapeutic or sham CPAP, did not observe any change in glucose, lipids, insulin resistance or the proportion of patients with metabolic syndrome. In summary, these recent data suggest that CPAP is able to reduce systemic inflammation, improve endothelial function and restore insulin sensitivity in lean OSA, but has a less significant impact on metabolic dysfunction in obese OSA.

Another intriguing confounding factor relates to sleep duration. There is now substantial evidence linking sleep duration with obesity and diabetes [103-106]. There are also studies 
showing a strong relationship between sleep duration and hypertension risk [107, 108]. The mechanisms relating sleep deprivation and both metabolic and cardiovascular morbid conditions may rely on inflammation [109], and these mechanisms are currently under investigation [110]. However, the exact contribution of sleep duration to sleep apnoea comorbidity remains unknown.

The other stimuli occurring during sleep apnoea (i.e. sleep fragmentation, repetitive episodes of hypercapnia and respiratory efforts) may also contribute to chronic consequences. Their acute impact on the autonomic nervous system is well established [111]. Whether or not sleep fragmentation or respiratory efforts contribute to chronic morbidity is still poorly understood. Sleep fragmentation seems to be associated with both inflammation and prothrombotic factors at the plasmatic level [112]. This could have an additive effect to the impact of nocturnal hypoxia. With respect to respiratory efforts, as reflected by the changes in intrathoracic pressure occurring during OSA, it might also offset the normal fall in BP that occurs overnight, as evidenced in a community population [113].

\section{CSA SYNDROME WITH CSR}

This is a condition including both central apnoeas and hypopnoeas and CSR that is usually associated with an increase in ventilatory response to $\mathrm{CO}_{2}$, promoting ventilatory and thus sleep instability [1]. The most prevalent condition leading to CSR with CSA (CSR-CSA) is CHF, being both a marker of severity and a factor of aggravation affecting both morbidity and mortality [114].

\section{Prevalence}

There is still much debate regarding the prevalence and incidence of CSR-CSA. The reported prevalences of CSR-CSA in CHF patients widely range $30-100 \%$. The first large study included 450 people with CHF, and reported a 38 and $33 \%$ prevalence of OSAS and CSA syndrome, respectively, when using an AHI cut-off of 10 events $\cdot h^{-1}$ during sleep [115]. These differences in various CHF populations may be explained by the size of the sample studied, patient selection, the stability of the disease and the criteria used to score hypopnoeas. More recently, JAVAHERI [116] reported on a prospective study of 100 patients out of 114 consecutive eligible patients with heart failure and a left ventricular ejection fraction (LVEF) of $<45 \%$. Of these patients, $49 \%$ had sleep apnoea, with a mean AHI of 49 events $\cdot h^{-1}, 37 \%$ had CSR-CSA and $12 \%$ had OSA. In this study, the hallmarks of CSR-CSA were New York Heart Association (NYHA) functional class III, atrial fibrillation, frequent nocturnal ventricular arrhythmias, low arterial carbon dioxide tension $\left(\mathrm{Pa}_{\mathrm{a}} \mathrm{CO}_{2}\right)$ and an LVEF of $<20 \%$ [116]. Finally, the largest study was published in 2007 and included 700 patients. These patients received $\beta$-blockers in $85 \%$ of cases. SDB was present in $76 \%$ of patients, $40 \%$ showing CSA and $36 \%$ showing OSA. CSR-CSA patients were more symptomatic (NYHA functional class $2.9 \pm 0.5$ versus $2.57 \pm 0.5$ with no SDB or $2.57 \pm 0.5$ with OSA; $\mathrm{p}<0.05$ ) and exhibited a lower LVEF than OSA patients $(27.4 \pm 6.6$ versus $29.3 \pm 2.6 \%$; $<<0.05)$ [117].

One critical and highly discussed question is whether or not the high incidence of CSR-CSA persists despite the newest treatments for heart failure. The relationships between $\beta$ blocker treatment and CSR-CSA have, for instance, been investigated in terms of SDB severity [118]. Among 45 patients with CHF (NYHA functional class II/III and LVEF of $<50 \%$ ), patients receiving $\beta$-blockers showed a lower AHI and central apnoea index than patients not receiving $\beta$-blockers. Multiple regression analysis selected no use of $\beta$-blockers as an independent factor for central apnoea index. These results suggest that $\beta$-blocker therapy may dose-dependently suppress CSR-CSA in patients with CHF [118], although this is not consistent with the latest large studies in the field showing a persistently high prevalence of CSR-CSA despite a high rate of use of $\beta$-blockers [117, 119].

\section{Pathophysiology}

Heart failure leads to an increased left ventricular filling pressure. The resulting pulmonary congestion activates lung vagal irritant receptors, thus leading to hyperventilation and hypocapnia. Superimposed arousals cause further abrupt increases in ventilation, and drive the $\mathrm{Pa}_{\mathrm{a}} \mathrm{CO}_{2}$ below the threshold for ventilation, triggering central events. CSAs are sustained by recurrent arousals resulting from apnoea-induced hypoxia and the increased effort of breathing during the ventilatory phase because of pulmonary congestion and reduced lung compliance. Although central apnoeas exhibit a different pathophysiology from obstructive apnoeas, and are not associated with the generation of exaggerated negative intrathoracic pressure, both acutely increase sympathetic nervous system activity [120]. However, in CHF patients with CSR-CSA, the chronic increase in muscle sympathetic nervous system activity is related more to the severity of heart failure than to the occurrence of CSR-CSA [121].

\section{Consequences}

An increase in sympathetic activity occurs during both heart failure and CSR-CSA. The relative contributions of heart failure and CSR-CSA remain the subject of discussion. Overnight sympathetic activity is significantly greater in $\mathrm{CHF}$ patients than in OSA patients. The haemodynamic severity of $\mathrm{CHF}$ contributes to the elevation of sympathetic activity in $\mathrm{CHF}$ patients to a greater degree than the apnoea-related hypoxaemia [122]. In addition, other important biological markers of CHF have been shown to be affected by CSR. This is the case for atrial natriuretic peptide, B-type natriuretic peptide and ET, underlining the complex relationship that exists between the respective mechanisms of CHF and CSR [123-125].

An association between CSR-CSA and ventricular ectopy has also been suggested, and a cause-effect relationship evidenced [126]. Ventricular premature beat frequency was also found to be higher during periods of CSR-CSA than during periods of regular breathing, either occurring spontaneously or induced through inhalation of $\mathrm{CO}_{2}$. This increase in ventricular premature beats might contribute to the higher mortality rates reported in heart failure patients with CSR-CSA. Atrial fibrillation (AF) has been shown to occur frequently in $\mathrm{CHF}$ patients with CSR-CSA [115, 127]. It has been evidenced that AF represents a predictive factor for CSR-CSA and also a risk factor for decreasing cardiac output when treating these subjects with CPAP [128]. LEUNG et al. [129] showed a markedly increased prevalence of AF among patients with idiopathic CSA in the absence of CHF. This high AF prevalence 
was not explainable by the presence of hypertension or nocturnal oxygen desaturation, since both factors were more strongly associated with OSA. This, therefore, favours a specific role of CSR-CSA in promoting AF independently of $\mathrm{CHF}$, with the mechanisms remaining to be elucidated.

All of these factors, i.e. sympathetic activation and other biological changes, ventricular ectopy and AF, may act, in variable part, as deleterious factors regarding cardiac function and contribute to aggravate heat failure. Thus, there is a rationale for viewing CSR-CSA not only as a marker of the severity of $\mathrm{CHF}$ but also as a risk factor for heart failure aggravation. Sympathetic activation, in increasing BP and cardiac frequency, increases myocardial oxygen demand in the face of reduced supply. This chain of events contributes to a pathophysiological vicious cycle [130].

CSR-CSA may, for these reasons and independently of other risk factors, elevate the risk of mortality in CHF two- or threefold [131, 132]. However, there are not many evidence-based studies so this has been challenged. In a recent study of 78 patients aged $53 \pm 9$ yrs with an LVEF of $19.9 \pm 7.2 \%, 29 \%$ had no apnoea, $28 \%$ had OSA and $42 \%$ had CSR-CSA at baseline. At 52 months, their overall mortality was $40 \%$ and the event rate (death or heart transplantation) was $72 \%$. Mortality rates were similar between the three apnoea groups. Moreover, survivors had a similar prevalence of SDB (71\%) to nonsurvivors $(70 \%)$, and multivariate analysis identified transplantation but not SDB type or severity as a significant predictor of survival [133]. There are very recent data, however, to support a significant impact of CSR-CSA on mortality [132]. Patients with systolic heart failure presenting with or without CSR-CSA $(n=88)$ were followed for 51 months. Their mean AHI was $34 \pm 25$ events $\cdot h^{-1}$, with mainly central apnoeas. The median survival of patients with CSR-CSA was 45 months compared with 90 months for those without CSR-CSA. The other two variables that correlated with poor survival were severity of right ventricular systolic dysfunction and low diastolic BP. Overall, there is evidence for increased morbidity and possibly mortality in CHF patients presenting with CSR-CSA. It is, however, mandatory that this be firmly established in large-scale studies. However, another means of demonstrating such a link is to look at CSR-CSA treatment effects.

\section{Treatment}

Short-term CPAP application, in patients with stable CHF, has been shown to reduce left ventricular afterload [134], increase stroke volume in patients with an elevated left ventricular filling pressure [135] and reduce adrenergic tone [136]. Longterm nightly use of CPAP over 1-3 months has been shown to alleviate CSR-CSA [137, 138], increase LVEF [139] and inspiratory muscle strength [140], and reduce mitral regurgitation, atrial natriuretic peptide levels [123] and adrenergic tone [141]. It has also been shown to improve quality of life [139]. Furthermore, there is evidence, in patients with CHF and CSRCSA, that nightly administration of CPAP can attenuate CSRCSA, improve cardiac function and alleviate symptoms of heart failure [139]. It has also been suggested that CPAP can reduce the combined mortality-cardiac transplantation rate in those CHF patients with CSR-CSA who comply with therapy [131]. However, the major limitation of these trials was the inclusion of only small samples. Thus, the Canadian Continuous Positive Airway Pressure for Patients with Central Sleep Apnea and Heart Failure trial represented the first large-scale randomised controlled trial performed in the field. The first report did not confirm any reduction in mortality, although there was a significant improvement in heart function. This was related to an initial increase in mortality that remained unexplained in the initial report [142]. However, a complementary analysis has recently been performed, published in 2007, demonstrating that the correction of respiratory events observed in part of this CSR-CSA population under CPAP led to a significant improvement in mortality in the CPAP responders [143]. This finding certainly supports a critical role for CSR-CSA in heart failure outcome, although it needs further confirmation in further randomised controlled trials. Moreover, other modes of positive airway pressure, such as assisted servo-ventilation, being apparently more acceptable to heart failure patients and more effective in CSR-CSA and for heart function [114, 144], are currently under investigation in large multicentric controlled trials.

\section{Establishing the role of hypoxia in this context}

Although there are very few specific data, several issues can be raised. There is a contribution of nocturnal hypoxia in promoting sympathetic activity in CSR-CSA. The additive effect of CSR-CSA to sympathetic activity in heart failure has been demonstrated previously [145]. Nocturnal hypoxia is likely to play a role in this context. Indeed, the reversibility of this sympathetic activation during CPAP is also of importance [141]. When applying CPAP, although there is a clear mechanical effect in reducing left ventricular transmural pressure, the beneficial effect on sympathetic activity, cardiac function and overall outcome appears exclusively in heart failure patients with CSR-CSA, when compared with patients without CSR-CSA [131]. Finally, it is of major importance to note that only CPAP-treated heart failure patients being corrected for their respiratory events exhibit a significant improvement in outcome [143]. Thus, although hypoxia is usually moderate and less severe in CSR-CSA compared to OSA, it also seems critical in this context.

\section{OBESITY HYPOVENTILATION SYNDROME}

OHS includes both obesity and daytime hypercapnia [1], and involves either hypoventilation, apnoeas or both during sleep. Such patients exhibit undiagnosed daytime hypercapnia [146]. They also frequently present with pulmonary hypertension and cor pulmonale [147]. Use of healthcare resources [148], rates of hospitalisation and early mortality are increased in OHS patients [146]. Noninvasive ventilation (NIV) is the firstline therapy in patients with OHS [149]. Patients show good compliance rates with NIV [150], and the therapy is effective in terms of clinical status and blood gas improvements [149-151].

The pathophysiology of OHS results from complex interactions, among which are increased work of breathing related to obesity, normal or diminished ventilatory drive, various associated SDB (i.e. obstructive apnoeas and rapid eye movement sleep hypoventilation) and neurohormonal changes, such as leptin resistance [147]. Leptin is produced primarily by white adipose tissue. This hormone elicits appetite suppression and weight loss. Circulating plasma leptin levels reflect the 
amount of energy storage in adipose tissue and increase exponentially with increasing fat mass. Plasma leptin levels also respond to short-term energy imbalance, increasing during periods of overfeeding and decreasing with fasting. The hormone activates specific receptors located at several sites throughout the brain but plays a key role at the hypothalamus, in particular, where it alters the expression of several hypothalamic neuropeptides. One of the most important, neuropeptide Y (NPY), is a potent stimulator of food intake and activator of the hypothalamic-pituitary-gonadal axis. Leptin inhibits synthesis of hypothalamic NPY, and downregulation of NPY is associated with appetite suppression, increased sympathetic nervous system outflow and increased energy expenditure. Increased leptin levels activate the thyroid hormone, gonadal and growth hormone axes and suppress the pituitary-adrenal axis. Circulating leptin levels are typically higher than normal in human obesity, indicating and contributing to a leptin-resistant state. This resistant state is partial, since there is a loss of appetite suppression during which the increase in sympathetic activity is maintained [152].

Apart from its anti-obesity effects, leptin exerts important physiological effects on the control of respiration [153]. Mice lacking the gene responsible for production of leptin $(o b / o b$ mice) demonstrate hypoventilation in addition to marked obesity. Furthermore, these animals exhibit an impaired hypercapnic ventilatory response (HCVR) during both wakefulness and sleep [154]. During rapid eye movement sleep, the HCVR is absent in $o b / o b$ mice. This HCVR impairment in $o b / o b$ relative to wild-type mice cannot be attributed to the mechanical effects of obesity since it precedes the development of the latter. Furthermore, leptin replacement studies in $o b / o b$ mice have shown improvements in baseline minute ventilation and HCVR during wakefulness and sleep under experimental conditions that prevented a concomitant weight change in the animal [152, 154]. Most patients with OHS suffer from OSA, and, in many (but not all) cases, treatment of OSA with nasal CPAP restores daytime eucapnia. In some patients, OHS cannot be explained on the basis of OSA, and daytime hypercapnia appears to result from inadequate physiological compensation for the development of obesity alone. Thus leptin may play a central role in OHS pathophysiology with respect to $\mathrm{CO}_{2}$ response [147, 155-159] and also OHSassociated morbidity. Leptin may be a modulator of respiratory drive in both obese [157] and OHS patients [158]. NIV, the first-line treatment in OHS, results in improvement in daytime and night-time blood gas levels, $\mathrm{CO}_{2}$ ventilatory response and serum leptin levels [147, 155, 158]. There is also an improvement in vigilance, linked to the $\mathrm{CO}_{2}$ response changes under NIV [160]. Both vigilance and cardiovascular morbidity may be dependent upon leptin, as well as on other inflammatory cytokines (see later).

Indeed, adipose tissue is able to express numerous other adipokines that are involved in energy homeostasis, as well as in vascular and endothelial physiology (TNF- $\alpha$, interleukin-6, complement factors, angiotensinogen, resistin, adipocyte differentiation factor and nitric oxide; fig. 3). These adipokines are thought to be the mediators of endothelial injury and atherosclerosis. Although most adipokines promote insulin resistance and endothelial dysfunction, adiponectin protects against these disorders. Adiponectin levels are decreased in

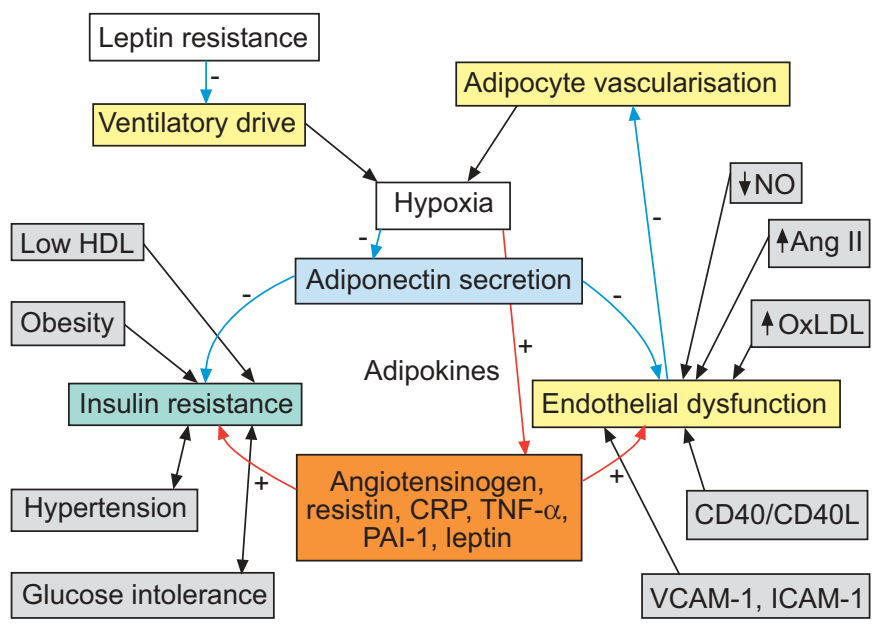

FIGURE 3. Effect of hypoxia on adipokines and their interactions with insulin metabolism and endothelial function. The main factors involved are leptin, angiotensinogen (Ang), resistin, C-reactive protein (CRP), tumour necrosis factor (TNF)- $\alpha$ and plasminogen activator inhibitor-1 (PAl-1). Leptin promotes (red arrows) insulin resistance and endothelial dysfunction, whereas adiponectin is protective (blue arrows). Obesity, a state of leptin resistance and endothelial dysfunction, also exhibits hypoxia, which is known to activate (red arrow) promoting adipokines and inhibit (blue arrows) adiponectin production. In obesity hypoventilation syndrome, obesity and night-time hypoxia and hypercapnia might act synergistically in producing inflammation at the systemic and vascular level, and in promoting metabolic and cardiovascular dysfunction. HDL: high-density lipoprotein; OxLDL: oxidised low-density lipoprotein; CD40L: CD40 ligand; VCAM-1: vascular cel adhesion molecule-1; ICAM-1: intercellular adhesion molecule-1; +: activation/ promotion; -: inhibition/protection; $\downarrow$ : decrease; $\uparrow$ : increase. Modified from [161] with permission from the publisher.

obesity [162] and inversely correlate with cardiovascular morbidity. With both systemic hypoxia and tissue ischaemia, adipokine levels are altered, with downregulation of adiponectin expression [163] and upregulation of plasminogen activator inhibitor-1 [164] and leptin through hypoxia-inducible factor $1 \alpha$ activation.

Thus, in obesity hypoventilation, a condition in which resistance to leptin, obesity and, usually, severe nocturnal hypoxia occur, there is possible insulin resistance and endothelial dysfunction resulting from systemic and adipose tissue hypoxia. The role of nocturnal hypoxia resulting from nocturnal hypoventilation and recurrent apnoeas, when present, may be critical. It might explain, at least partly, the excess of morbidity and mortality occurring in OHS.

\section{CONCLUSIONS}

The hypoxic insult occurring during sleep-disordered breathing varies from one condition to another. However, there are common cardiovascular and metabolic morbidities in these various conditions. There are major differences with continuous hypoxia, suggesting specific pathways originating from the occurrence of oxidative stress and inflammatory cascade activation. Hypoxia seems to be the major factor in morbidity. Despite the great scientific advances of the past years in this field, the cellular and molecular mechanisms involved during intermittent hypoxia remain to be fully elucidated. 


\section{REFERENCES}

1 Sleep-related breathing disorders in adults: recommendations for syndrome definition and measurement techniques in clinical research. The Report of an American Academy of Sleep Medicine Task Force. Sleep 1999; 22: 667-689.

2 International Classification of Sleep Disorders. Diagnostic and Coding Manual. 2nd Edn. Rochester, American Academy of Sleep Medicine, 2005.

3 Guilleminault C, Stoohs R, Clerk A, Cetel M, Maistros P. A cause of excessive daytime sleepiness. The upper airway resistance syndrome. Chest 1993; 104: 781-787.

4 Young T, Peppard PE, Gottlieb DJ. Epidemiology of obstructive sleep apnea: a population health perspective. Am J Respir Crit Care Med 2002; 165: 1217-1239.

5 Young T, Palta M, Dempsey J, Skatrud J, Weber S, Badr S. The occurrence of sleep-disordered breathing among middle-aged adults. N Engl J Med 1993; 328: 1230-1235.

6 Teran-Santos J, Jimenez-Gomez A, Cordero-Guevara J, for The Cooperative Group Burgos-Santander. The association between sleep apnea and the risk of traffic accidents. N Engl J Med 1999; 340: 847-851.

7 Levy P, Pepin JL, McNicholas WT. Should all sleep apnoea patients be treated? Yes. Sleep Med Rev 2002; 6: 17-26.

8 Marin JM, Carrizo SJ, Vicente E, Agusti AG. Long-term cardiovascular outcomes in men with obstructive sleep apnoea-hypopnoea with or without treatment with continuous positive airway pressure: an observational study. Lancet 2005; 365: 1046-1053.

9 Pepperell JC, Ramdassingh-Dow S, Crosthwaite N, et al. Ambulatory blood pressure after therapeutic and subtherapeutic nasal continuous positive airway pressure for obstructive sleep apnoea: a randomised parallel trial. Lancet 2002; 359: 204-210.

10 Drager LF, Bortolotto LA, Lorenzi MC, Figueiredo AC, Krieger EM, Lorenzi-Filho G. Early signs of atherosclerosis in obstructive sleep apnea. Am J Respir Crit Care Med 2005; 172: 613-618.

11 Baguet JP, Hammer L, Levy $\mathrm{P}$, et al. The severity of oxygen desaturation is predictive of carotid wall thickening and plaque occurrence. Chest 2005; 128: 3407-3412.

12 Lavie P, Herer P, Peled R, et al. Mortality in sleep apnea patients: a multivariate analysis of risk factors. Sleep 1995; 18: 149-157.

13 Lavie L. Obstructive sleep apnoea syndrome - an oxidative stress disorder. Sleep Med Rev 2003; 7: 35-51.

14 Lavie L, Vishnevsky A, Lavie P. Evidence for lipid peroxidation in obstructive sleep apnea. Sleep 2004; 27: 123-128.

15 Barcelo A, Miralles C, Barbe F, Vila M, Pons S, Agusti AG. Abnormal lipid peroxidation in patients with sleep apnoea. Eur Respir J 2000; 16: 644-647.

16 Svatikova A, Wolk R, Lerman LO, et al. Oxidative stress in obstructive sleep apnoea. Eur Heart J 2005; 26: 24352439.

17 Ohga E, Tomita T, Wada H, Yamamoto H, Nagase T, Ouchi Y. Effects of obstructive sleep apnea on circulating ICAM-1, IL-8, and MCP-1. J Appl Physiol 2003; 94: 179-184.

18 Schulz R, Mahmoudi S, Hattar K, et al. Enhanced release of superoxide from polymorphonuclear neutrophils in obstructive sleep apnea. Impact of continuous positive airway pressure therapy. Am J Respir Crit Care Med 2000; 162: 566-570.

19 Ciftci TU, Kokturk O, Bukan N, Bilgihan A. The relationship between serum cytokine levels with obesity and obstructive sleep apnea syndrome. Cytokine 2004; 28: 87-91.

20 Nieto FJ, Herrington DM, Redline S, Benjamin EJ, Robbins JA. Sleep apnea and markers of vascular endothelial function in a large community sample of older adults. Am J Respir Crit Care Med 2004; 169: 354-360.

21 Itzhaki S, Lavie L, Pillar G, Tal G, Lavie P. Endothelial dysfunction in obstructive sleep apnea measured by peripheral arterial tone response in the finger to reactive hyperemia. Sleep 2005; 28: 594-600.

22 Punjabi NM, Ahmed MM, Polotsky VY, Beamer BA, O'Donnell CP. Sleep-disordered breathing, glucose intolerance, and insulin resistance. Respir Physiol Neurobiol 2003; 136: 167-178.

23 Barcelo A, Barbe F, de la Pena M, et al. Antioxidant status in patients with sleep apnoea and impact of continuous positive airway pressure treatment. Eur Respir J 2006; 27: 756-760.

24 Faure P, Tamisier R, Baguet JP, et al. Impairment of serum albumin antioxidant properties in obstructive sleep apnoea syndrome. Eur Respir J 2008; 31: 1046-1053.

25 Zou MH, Hou XY, Shi CM, Nagata D, Walsh K, Cohen RA. Modulation by peroxynitrite of Akt- and AMP-activated kinase-dependent Ser ${ }^{1179}$ phosphorylation of endothelial nitric oxide synthase. J Biol Chem 2002; 277: 32552-32557.

26 Kocis JM, Kuo WN, Liu Y, Guruvadoo LK, Langat JL. Regulation of catalase: inhibition by peroxynitrite and reactivation by reduced glutathione and glutathione S-transferase. Front Biosci 2002; 7: a175-a180.

27 Schulz R, Schmidt D, Blum A, et al. Decreased plasma levels of nitric oxide derivatives in obstructive sleep apnoea: response to CPAP therapy. Thorax 2000; 55: 1046-1051.

28 Lavie L, Hefetz A, Luboshitzky R, Lavie P. Plasma levels of nitric oxide and L-arginine in sleep apnea patients: effects of nCPAP treatment. J Mol Neurosci 2003; 21: 57-63.

29 Svatikova A, Wolk R, Wang $\mathrm{HH}$, et al. Circulating free nitrotyrosine in obstructive sleep apnea. Am J Physiol Regul Integr Comp Physiol 2004; 287: R284-R287.

30 Ryan S, Taylor CT, McNicholas WT. Selective activation of inflammatory pathways by intermittent hypoxia in obstructive sleep apnea syndrome. Circulation 2005; 112: 2660-2667.

31 Shamsuzzaman AS, Winnicki $\mathrm{M}$, Lanfranchi $\mathrm{P}$, et al. Elevated C-reactive protein in patients with obstructive sleep apnea. Circulation 2002; 105: 2462-2464.

32 Yokoe T, Minoguchi K, Matsuo H, et al. Elevated levels of C-reactive protein and interleukin-6 in patients with obstructive sleep apnea syndrome are decreased by nasal continuous positive airway pressure. Circulation 2003; 107: 1129-1134.

33 Larkin EK, Rosen CL, Kirchner HL, et al. Variation of Creactive protein levels in adolescents: association with 
sleep-disordered breathing and sleep duration. Circulation 2005; 111: 1978-1984.

34 Guilleminault C, Kirisoglu C, Ohayon MM. C-reactive protein and sleep-disordered breathing. Sleep 2004; 27: 1507-1511.

35 Dyugovskaya L, Lavie P, Lavie L. Increased adhesion molecules expression and production of reactive oxygen species in leukocytes of sleep apnea patients. Am J Respir Crit Care Med 2002; 165: 934-939.

36 Lavie L, Dyugovskaya L, Lavie P. Sleep-apnea-related intermittent hypoxia and atherogenesis: adhesion molecules and monocytes/endothelial cells interactions. Atherosclerosis 2005; 183: 183-184.

37 Dyugovskaya L, Lavie P, Lavie L. Phenotypic and functional characterization of blood $\gamma \delta \mathrm{T}$ cells in sleep apnea. Am J Respir Crit Care Med 2003; 168: 242-249.

38 El Solh AA, Akinnusi ME, Baddoura FH, Mankowski CR. Endothelial cell apoptosis in obstructive sleep apnea: a link to endothelial dysfunction. Am J Respir Crit Care Med 2007; 175: 1186-1191.

39 Prabhakar NR. Oxygen sensing during intermittent hypoxia: cellular and molecular mechanisms. I Appl Physiol 2001; 90: 1986-1994.

40 Vgontzas AN, Papanicolaou DA, Bixler EO, Kales A, Tyson K, Chrousos GP. Elevation of plasma cytokines in disorders of excessive daytime sleepiness: role of sleep disturbance and obesity. J Clin Endocrinol Metab 1997; 82: 1313-1316.

41 Teramoto S, Yamamoto H, Ouchi Y. Increased C-reactive protein and increased plasma interleukin-6 may synergistically affect the progression of coronary atherosclerosis in obstructive sleep apnea syndrome. Circulation 2003; 107: e40.

42 Vgontzas AN, Bixler EO, Chrousos GP. Sleep apnea is a manifestation of the metabolic syndrome. Sleep Med Rev 2005; 9: 211-224.

43 Baumgardner JE, Otto CM. In vitro intermittent hypoxia: challenges for creating hypoxia in cell culture. Respir Physiol Neurobiol 2003; 136: 131-139.

44 Peng Y, Yuan G, Overholt JL, Kumar GK, Prabhakar NR. Systemic and cellular responses to intermittent hypoxia: evidence for oxidative stress and mitochondrial dysfunction. Adv Exp Med Biol 2003; 536: 559-564.

45 Kumar GK, Kim DK, Lee MS, Ramachandran R, Prabhakar NR. Activation of tyrosine hydroxylase by intermittent hypoxia: involvement of serine phosphorylation. J Appl Physiol 2003; 95: 536-544.

46 Kimoff RJ, Makino H, Horner RL, et al. Canine model of obstructive sleep apnea: model description and preliminary application. J Appl Physiol 1994; 76: 1810-1817.

47 Brooks D, Horner RL, Kozar LF, Render-Teixeira CL, Phillipson EA. Obstructive sleep apnea as a cause of systemic hypertension. Evidence from a canine model. J Clin Invest 1997; 99: 106-109.

48 Brooks D, Horner RL, Kimoff RJ, Kozar LF, RenderTeixeira CL, Phillipson EA. Effect of obstructive sleep apnea versus sleep fragmentation on responses to airway occlusion. Am J Respir Crit Care Med 1997; 155: 1609-1617.

49 Powell FL. Functional genomics and the comparative physiology of hypoxia. Annu Rev Physiol 2003; 65: 203-230.
50 Neubauer JA. Invited review: physiological and pathophysiological responses to intermittent hypoxia. J Appl Physiol 2001; 90: 1593-1599.

51 Fletcher EC, Lesske J, Qian W, Miller CC 3rd, Unger T. Repetitive, episodic hypoxia causes diurnal elevation of blood pressure in rats. Hypertension 1992; 19: 555-561.

52 Fletcher EC, Bao G, Li R. Renin activity and blood pressure in response to chronic episodic hypoxia. Hypertension 1999; 34: 309-314.

53 Julien C, Bayat S, Levy P. Vascular reactivity to norepinephrine and acetylcholine after chronic intermittent hypoxia in mice. Respir Physiol Neurobiol 2003; 139: 21-32.

54 Lefebvre B, Godin-Ribuot D, Joyeux-Faure M, et al. Functional assessment of vascular reactivity after chronic intermittent hypoxia in the rat. Respir Physiol Neurobiol 2006; 150: 278-286.

55 Greenberg HE, Sica A, Batson D, Scharf SM. Chronic intermittent hypoxia increases sympathetic responsiveness to hypoxia and hypercapnia. J Appl Physiol 1999; 86: 298-305.

56 Brooks D, Horner RL, Floras JS, Kozar LF, RenderTeixeira CL, Phillipson EA. Baroreflex control of heart rate in a canine model of obstructive sleep apnea. Am J Respir Crit Care Med 1999; 159: 1293-1297.

57 McGuire M, Bradford A. Chronic intermittent hypercapnic hypoxia increases pulmonary arterial pressure and haematocrit in rats. Eur Respir J 2001; 18: 279-285.

58 Kraiczi H, Magga J, Sun XY, Ruskoaho H, Zhao X, Hedner J. Hypoxic pressor response, cardiac size, and natriuretic peptides are modified by long-term intermittent hypoxia. J Appl Physiol 1999; 87: 2025-2031.

59 Phillips SA, Olson EB, Morgan BJ, Lombard JH. Chronic intermittent hypoxia impairs endothelium-dependent dilation in rat cerebral and skeletal muscle resistance arteries. Am J Physiol Heart Circ Physiol 2004; 286: H388H393.

60 Allahdadi KJ, Walker BR, Kanagy NL. Augmented endothelin vasoconstriction in intermittent hypoxiainduced hypertension. Hypertension 2005; 45: 705-709.

61 Beguin PC, Joyeux-Faure M, Godin-Ribuot D, Levy P, Ribuot C. Acute intermittent hypoxia improves rat myocardium tolerance to ischemia. J Appl Physiol 2005; 99: 1064-1069.

62 Joyeux-Faure M, Stanke-Labesque F, Lefebvre B, et al. Chronic intermittent hypoxia increases infarction in the isolated rat heart. J Appl Physiol 2005; 98: 1691-1696.

63 Volgin DV, Kubin L. Chronic intermittent hypoxia alters hypothalamic transcription of genes involved in metabolic regulation. Auton Neurosci 2006; 126-127: 93-99.

64 Li J, Thorne LN, Punjabi NM, et al. Intermittent hypoxia induces hyperlipidemia in lean mice. Circ Res 2005; 97: 698-706.

65 Dematteis M, Julien C, Guillermet C, et al. Intermittent hypoxia induces early functional cardiovascular remodeling in mice. Am J Respir Crit Care Med 2008; 177: 227-235.

66 Savransky V, Nanayakkara A, Li J, et al. Chronic intermittent hypoxia induces atherosclerosis. Am J Respir Crit Care Med 2007; 175: 1290-1297.

$67 \mathrm{Li}$ J, Savransky V, Nanayakkara A, Smith PL, O’Donnell CP, Polotsky VY. Hyperlipidemia and lipid 
peroxidation are dependent on the severity of chronic intermittent hypoxia. J Appl Physiol 2007; 102: 557-563.

68 Iiyori N, Alonso LC, Li J, et al. Intermittent hypoxia causes insulin resistance in lean mice independent of autonomic activity. Am J Respir Crit Care Med 2007; 175: 851-857.

69 Ling L, Fuller DD, Bach KB, Kinkead R, Olson EB Jr, Mitchell GS. Chronic intermittent hypoxia elicits serotonin-dependent plasticity in the central neural control of breathing. J Neurosci 2001; 21: 5381-5388.

70 Baker TL, Mitchell GS. Episodic but not continuous hypoxia elicits long-term facilitation of phrenic motor output in rats. J Physiol 2000; 529: 215-219.

71 McKay LC, Janczewski WA, Feldman JL. Episodic hypoxia evokes long-term facilitation of genioglossus muscle activity in neonatal rats. J Physiol 2004; 557: 13-18.

72 Clanton TL, Wright VP, Reiser PJ, Klawitter PF, Prabhakar NR. Selected contribution: improved anoxic tolerance in rat diaphragm following intermittent hypoxia. J Appl Physiol 2001; 90: 2508-2513.

73 Peng YJ, Overholt JL, Kline D, Kumar GK, Prabhakar NR. Induction of sensory long-term facilitation in the carotid body by intermittent hypoxia: implications for recurrent apneas. Proc Natl Acad Sci USA 2003; 100: 10073-10078.

74 Gozal D, Daniel JM, Dohanich GP. Behavioral and anatomical correlates of chronic episodic hypoxia during sleep in the rat. J Neurosci 2001; 21: 2442-2450.

75 Row BW, Liu R, Xu W, Kheirandish L, Gozal D. Intermittent hypoxia is associated with oxidative stress and spatial learning deficits in the rat. Am J Respir Crit Care Med 2003; 167: 1548-1553.

$76 \mathrm{Xu} \mathrm{W}$, Chi L, Row BW, et al. Increased oxidative stress is associated with chronic intermittent hypoxia-mediated brain cortical neuronal cell apoptosis in a mouse model of sleep apnea. Neuroscience 2004; 126: 313-323.

77 Zhan G, Serrano F, Fenik P, et al. NADPH oxidase mediates hypersomnolence and brain oxidative injury in a murine model of sleep apnea. Am J Respir Crit Care Med 2005; 172: 921-929.

78 Payne RS, Goldbart A, Gozal D, Schurr A. Effect of intermittent hypoxia on long-term potentiation in rat hippocampal slices. Brain Res 2004; 1029: 195-199.

79 Gozal E, Gozal D, Pierce WM, et al. Proteomic analysis of CA1 and CA3 regions of rat hippocampus and differential susceptibility to intermittent hypoxia. J Neurochem 2002; 83: 331-345.

80 Gozal D, Row BW, Gozal E, et al. Temporal aspects of spatial task performance during intermittent hypoxia in the rat: evidence for neurogenesis. Eur J Neurosci 2003; 18: 2335-2342.

81 Naegele B, Thouvard V, Pepin JL, et al. Deficits of cognitive executive functions in patients with sleep apnea syndrome. Sleep 1995; 18: 43-52.

82 Naegele B, Launois SH, Mazza S, Feuerstein C, Pepin JL, Levy P. Which memory processes are affected in patients with obstructive sleep apnea? An evaluation of 3 types of memory. Sleep 2006; 29: 533-544.

83 Naegele B, Pepin JL, Levy P, Bonnet C, Pellat J, Feuerstein C. Cognitive executive dysfunction in patients with obstructive sleep apnea syndrome (OSAS) after CPAP treatment. Sleep 1998; 21: 392-397.
84 Beebe DW, Gozal D. Obstructive sleep apnea and the prefrontal cortex: towards a comprehensive model linking nocturnal upper airway obstruction to daytime cognitive and behavioral deficits. J Sleep Res 2002; 11: 1-16.

85 Macey PM, Henderson LA, Macey KE, et al. Brain morphology associated with obstructive sleep apnea. Am J Respir Crit Care Med 2002; 166: 1382-1387.

86 Bartlett DJ, Rae C, Thompson CH, et al. Hippocampal area metabolites relate to severity and cognitive function in obstructive sleep apnea. Sleep Med 2004; 5: 593-596.

87 Mayer P, Dematteis M, Pepin JL, et al. Peripheral neuropathy in sleep apnea. A tissue marker of the severity of nocturnal desaturation. Am J Respir Crit Care Med 1999; 159: 213-219.

88 Baguet JP, Narkiewicz K, Mallion JM. Update on hypertension management: obstructive sleep apnea and hypertension. J Hypertens 2006; 24: 205-208.

89 Chobanian AV, Bakris GL, Black HR, et al. The Seventh Report of the Joint National Committee on Prevention, Detection, Evaluation, and Treatment of High Blood Pressure: the JNC 7 report. JAMA 2003; 289: 2560-2572.

90 Guilleminault C, Faul JL, Stoohs R. Sleep-disordered breathing and hypotension. Am J Respir Crit Care Med 2001; 164: 1242-1247.

91 Becker HF, Jerrentrup A, Ploch T, et al. Effect of nasal continuous positive airway pressure treatment on blood pressure in patients with obstructive sleep apnea. Circulation 2003; 107: 68-73.

92 Haentjens P, Van Meerhaeghe A, Moscariello A, et al. The impact of continuous positive airway pressure on blood pressure in patients with obstructive sleep apnea syndrome: evidence from a meta-analysis of placebocontrolled randomized trials. Arch Intern Med 2007; 167: 757-764.

93 Barbe F, Mayoralas LR, Duran J, et al. Treatment with continuous positive airway pressure is not effective in patients with sleep apnea but no daytime sleepiness: a randomized, controlled trial. Ann Intern Med 2001; 134: 1015-1023.

94 Robinson GV, Smith DM, Langford BA, Davies RJ, Stradling JR. Continuous positive airway pressure does not reduce blood pressure in nonsleepy hypertensive OSA patients. Eur Respir J 2006; 27: 1229-1235.

95 Minoguchi K, Yokoe T, Tazaki T, et al. Increased carotid intima-media thickness and serum inflammatory markers in obstructive sleep apnea. Am J Respir Crit Care Med 2005; 172: 625-630.

96 Drager LF, Bortolotto LA, Figueiredo AC, Krieger EM, Lorenzi-Filho G. Effects of continuous positive airway pressure on early signs of atherosclerosis in obstructive sleep apnea. Am J Respir Crit Care Med 2007; 176: 706-712.

97 Poirier P, Giles TD, Bray GA, et al. Obesity and cardiovascular disease: pathophysiology, evaluation, and effect of weight loss: an update of the 1997 American Heart Association Scientific Statement on Obesity and Heart Disease from the Obesity Committee of the Council on Nutrition, Physical Activity, and Metabolism. Circulation 2006; 113: 898-918.

98 Vgontzas AN, Papanicolaou DA, Bixler EO, et al. Sleep apnea and daytime sleepiness and fatigue: relation to 
visceral obesity, insulin resistance, and hypercytokinemia. J Clin Endocrinol Metab 2000; 85: 1151-1158.

99 Vgontzas AN, Bixler EO, Chrousos GP. Metabolic disturbances in obesity versus sleep apnoea: the importance of visceral obesity and insulin resistance. J Intern Med 2003; 254: 32-44.

100 Harsch IA, Schahin SP, Radespiel-Troger M, et al. Continuous positive airway pressure treatment rapidly improves insulin sensitivity in patients with obstructive sleep apnea syndrome. Am J Respir Crit Care Med 2004; 169: 156-162.

101 West SD, Nicoll DJ, Wallace TM, Matthews DR, Stradling JR. Effect of CPAP on insulin resistance and $\mathrm{HbA1c}$ in men with obstructive sleep apnoea and type 2 diabetes. Thorax 2007; 62: 969-974.

102 Coughlin SR, Mawdsley L, Mugarza JA, Wilding JP, Calverley PM. Cardiovascular and metabolic effects of CPAP in obese males with OSA. Eur Respir J 2007; 29: 720-727.

103 Mallon L, Broman J-E, Hetta J. High incidence of diabetes in men with sleep complaints or short sleep duration: a 12-year follow-up study of a middle-aged population. Diabetes Care 2005; 28: 2762-2767.

104 Taheri S, Lin L, Austin D, Young T, Mignot E. Short sleep duration is associated with reduced leptin, elevated ghrelin, and increased body mass index. PLoS Med 2004; 1: e62.

105 Spiegel K, Knutson K, Leproult R, Tasali E, Van Cauter E. Sleep loss: a novel risk factor for insulin resistance and type 2 diabetes. J Appl Physiol 2005; 99: 2008-2019.

106 Gottlieb DJ, Punjabi NM, Newman AB, et al. Association of sleep time with diabetes mellitus and impaired glucose tolerance. Arch Intern Med 2005; 165: 863-867.

107 Gottlieb DJ, Redline S, Nieto FJ, et al. Association of usual sleep duration with hypertension: the Sleep Heart Health Study. Sleep 2006; 29: 1009-1014.

108 Gangwisch JE, Heymsfield SB, Boden-Albala B, et al. Short sleep duration as a risk factor for hypertension: analyses of the first National Health and Nutrition Examination Survey. Hypertension 2006; 47: 833-839.

109 Meier-Ewert HK, Ridker PM, Rifai N, et al. Effect of sleep loss on C-reactive protein, an inflammatory marker of cardiovascular risk. J Am Coll Cardiol 2004; 43: 678-683.

110 Irwin $\mathrm{MR}$, Wang $\mathrm{M}$, Campomayor CO, ColladoHidalgo A, Cole S. Sleep deprivation and activation of morning levels of cellular and genomic markers of inflammation. Arch Intern Med 2006; 166: 1756-1762.

111 Smith RP, Veale D, Pepin JL, Levy PA. Obstructive sleep apnoea and the autonomic nervous system. Sleep Med Rev 1998; 2: 69-92.

112 von Kanel R, Loredo JS, Ancoli-Israel S, Mills PJ, Natarajan L, Dimsdale JE. Association between polysomnographic measures of disrupted sleep and prothrombotic factors. Chest 2007; 131: 733-739.

113 Stradling JR, Barbour C, Glennon J, Langford BA, Crosby JH. Which aspects of breathing during sleep influence the overnight fall of blood pressure in a community population? Thorax 2000; 55: 393-398.

114 Pepin JL, Chouri-Pontarollo N, Tamisier R, Levy P. Cheyne-Stokes respiration with central sleep apnoea in chronic heart failure: proposals for a diagnostic and therapeutic strategy. Sleep Med Rev 2006; 10: 33-47.

115 Sin DD, Fitzgerald F, Parker JD, Newton G, Floras JS, Bradley TD. Risk factors for central and obstructive sleep apnea in 450 men and women with congestive heart failure. Am J Respir Crit Care Med 1999; 160: 1101-1106.

116 Javaheri S. Sleep disorders in systolic heart failure: a prospective study of 100 male patients. The final report. Int J Cardiol 2006; 106: 21-28.

117 Oldenburg O, Lamp B, Faber L, Teschler H, Horstkotte D, Topfer V. Sleep-disordered breathing in patients with symptomatic heart failure: a contemporary study of prevalence in and characteristics of 700 patients. Eur J Heart Fail 2007; 9: 251-257.

118 Tamura A, Kawano Y, Naono S, Kotoku M, Kadota J-I. Relationship between $\beta$-blocker treatment and the severity of central sleep apnea in chronic heart failure. Chest 2007; 131: 130-135.

119 Javaheri S, Shukla R, Zeigler H, Wexler L. Central sleep apnea, right ventricular dysfunction, and low diastolic blood pressure are predictors of mortality in systolic heart failure. J Am Coll Cardiol 2007; 49: 2028-2034.

120 Somers VK, Dyken ME, Skinner JL. Autonomic and hemodynamic responses and interactions during the Mueller maneuver in humans. J Auton Nerv Syst 1993; 44: 253-259.

121 Mansfield D, Kaye DM, Brunner La Rocca H, Solin P, Esler MD, Naughton MT. Raised sympathetic nerve activity in heart failure and central sleep apnea is due to heart failure severity. Circulation 2003; 107: 1396-1400.

122 Solin P, Kaye DM, Little PJ, Bergin P, Richardson M, Naughton MT. Impact of sleep apnea on sympathetic nervous system activity in heart failure. Chest 2003; 123: 1119-1126.

123 Tkacova R, Liu PP, Naughton MT, Bradley TD. Effect of continuous positive airway pressure on mitral regurgitant fraction and atrial natriuretic peptide in patients with heart failure. J Am Coll Cardiol 1997; 30: 739-745.

124 Carmona-Bernal C, Quintana-Gallego E, Villa-Gil M, Sanchez-Armengol A, Martinez-Martinez A, Capote F. Brain natriuretic peptide in patients with congestive heart failure and central sleep apnea. Chest 2005; 127: 1667-1673.

125 El-Solh AA, Bozkanat E, Mador J, Grant BJ. Association between plasma endothelin-1 levels and Cheyne-Stokes respiration in patients with congestive heart failure. Chest 2002; 121: 1928-1934.

126 Leung RS, Diep TM, Bowman ME, Lorenzi-Filho G, Bradley TD. Provocation of ventricular ectopy by Cheyne-Stokes respiration in patients with heart failure. Sleep 2004; 27: 1337-1343.

127 Javaheri S, Parker TJ, Liming JD, et al. Sleep apnea in 81 ambulatory male patients with stable heart failure. Types and their prevalences, consequences, and presentations. Circulation 1998; 97: 2154-2159.

128 Liston R, Deegan PC, McCreery C, Costello R, Maurer B, McNicholas WT. Haemodynamic effects of nasal continuous positive airway pressure in severe congestive heart failure. Eur Respir J 1995; 8: 430-435. 
129 Leung RS, Huber MA, Rogge T, Maimon N, Chiu KL, Bradley TD. Association between atrial fibrillation and central sleep apnea. Sleep 2005; 28: 1543-1546.

130 Leung RS, Bradley TD. Sleep apnea and cardiovascular disease. Am J Respir Crit Care Med 2001; 164: 2147-2165.

131 Sin DD, Logan AG, Fitzgerald FS, Liu PP, Bradley TD. Effects of continuous positive airway pressure on cardiovascular outcomes in heart failure patients with and without Cheyne-Stokes respiration. Circulation 2000; 102: 61-66.

132 Javaheri S, Shukla R, Zeigler H, Wexler L. Central sleep apnea, right ventricular dysfunction, and low diastolic blood pressure are predictors of mortality in systolic heart failure. J Am Coll Cardiol 2007; 49: 2028-2034.

133 Roebuck T, Solin P, Kaye DM, Bergin P, Bailey M, Naughton MT. Increased long-term mortality in heart failure due to sleep apnoea is not yet proven. Eur Respir J 2004; 23: 735-740.

134 Naughton MT, Rahman MA, Hara K, Floras JS, Bradley TD. Effect of continuous positive airway pressure on intrathoracic and left ventricular transmural pressures in patients with congestive heart failure. Circulation 1995; 91: 1725-1731.

135 Bradley TD, Holloway RM, McLaughlin PR, Ross BL, Walters J, Liu PP. Cardiac output response to continuous positive airway pressure in congestive heart failure. Am Rev Respir Dis 1992; 145: 377-382.

136 Kaye DM, Mansfield D, Aggarwal A, Naughton MT, Esler MD. Acute effects of continuous positive airway pressure on cardiac sympathetic tone in congestive heart failure. Circulation 2001; 103: 2336-2338.

137 Takasaki Y, Orr D, Popkin J, Rutherford R, Liu P, Bradley TD. Effect of nasal continuous positive airway pressure on sleep apnea in congestive heart failure. Am Rev Respir Dis 1989; 140: 1578-1584.

138 Naughton MT, Benard DC, Rutherford R, Bradley TD. Effect of continuous positive airway pressure on central sleep apnea and nocturnal $\mathrm{PCO}_{2}$ in heart failure. $\mathrm{Am} \mathrm{J}$ Respir Crit Care Med 1994; 150: 1598-1604.

139 Naughton MT, Liu PP, Bernard DC, Goldstein RS, Bradley TD. Treatment of congestive heart failure and Cheyne-Stokes respiration during sleep by continuous positive airway pressure. Am J Respir Crit Care Med 1995; 151: 92-97.

140 Granton JT, Naughton MT, Benard DC, Liu PP, Goldstein RS, Bradley TD. CPAP improves inspiratory muscle strength in patients with heart failure and central sleep apnea. Am J Respir Crit Care Med 1996; 153: 277-282.

141 Naughton MT, Benard DC, Liu PP, Rutherford R, Rankin F, Bradley TD. Effects of nasal CPAP on sympathetic activity in patients with heart failure and central sleep apnea. Am J Respir Crit Care Med 1995; 152: 473-479.

142 Bradley TD, Logan AG, Kimoff RJ, et al. Continuous positive airway pressure for central sleep apnea and heart failure. N Engl J Med 2005; 353: 2025-2033.

143 Arzt M, Floras JS, Logan AG, et al. Suppression of central sleep apnea by continuous positive airway pressure and transplant-free survival in heart failure: a post hoc analysis of the Canadian Continuous Positive Airway
Pressure for Patients with Central Sleep Apnea and Heart Failure trial (CANPAP). Circulation 2007; 115: 3173-3180.

144 Philippe C, Stoica-Herman M, Drouot X, et al. Compliance with and effectiveness of adaptive servoventilation versus continuous positive airway pressure in the treatment of Cheyne-Stokes respiration in heart failure over a six month period. Heart 2006; 92: 337-342.

145 Spaak J, Egri ZJ, Kubo T, et al. Muscle sympathetic nerve activity during wakefulness in heart failure patients with and without sleep apnea. Hypertension 2005; 46: 13271332.

146 Nowbar S, Burkart KM, Gonzales R, et al. Obesityassociated hypoventilation in hospitalized patients: prevalence, effects, and outcome. Am J Med 2004; 116: 1-7.

147 Olson AL, Zwillich C. The obesity hypoventilation syndrome. Am J Med 2005; 118: 948-956.

148 Berg G, Delaive K, Manfreda J, Walld R, Kryger MH. The use of health-care resources in obesity-hypoventilation syndrome. Chest 2001; 120: 377-383.

149 Masa JF, Celli BR, Riesco JA, Hernandez M, Sanchez De Cos J, Disdier C. The obesity hypoventilation syndrome can be treated with noninvasive mechanical ventilation. Chest 2001; 119: 1102-1107.

150 Janssens JP, Derivaz S, Breitenstein E, et al. Changing patterns in long-term noninvasive ventilation: a 7-year prospective study in the Geneva Lake area. Chest 2003; 123: 67-79.

151 Perez de Llano LA, Golpe R, Ortiz Piquer M, et al. Shortterm and long-term effects of nasal intermittent positive pressure ventilation in patients with obesity-hypoventilation syndrome. Chest 2005; 128: 587-594.

152 Phillips BG, Kato M, Narkiewicz K, Choe I, Somers VK. Increases in leptin levels, sympathetic drive, and weight gain in obstructive sleep apnea. Am J Physiol Heart Circ Physiol 2000; 279: H234-H237.

153 O'Donnell CP, Tankersley CG, Polotsky VP, Schwartz AR, Smith PL. Leptin, obesity, and respiratory function. Respir Physiol 2000; 119: 163-170.

154 O'Donnell CP, Schaub CD, Haines AS, et al. Leptin prevents respiratory depression in obesity. Am J Respir Crit Care Med 1999; 159: 1477-1484.

155 Redolfi S, Corda L, La Piana G, Spandrio S, Prometti P, Tantucci C. Long-term non-invasive ventilation increases chemosensitivity and leptin in obesity-hypoventilation syndrome. Respir Med 2007; 101: 1191-1195.

156 Phipps PR, Starritt E, Caterson I, Grunstein RR. Association of serum leptin with hypoventilation in human obesity. Thorax 2002; 57: 75-76.

157 Atwood CW. Sleep-related hypoventilation: the evolving role of leptin. Chest 2005; 128: 1079-1081.

158 Yee BJ, Cheung J, Phipps P, Banerjee D, Piper AJ, Grunstein RR. Treatment of obesity hypoventilation syndrome and serum leptin. Respiration 2006; 73: 209-212.

159 Campo A, Fruhbeck G, Zulueta JJ, et al. Hyperleptinemia, respiratory drive and hypercapnic response in obese patients. Eur Respir J 2007; 30: 223-231.

160 Chouri-Pontarollo N, Borel JC, Tamisier R, Wuyam B, Levy P, Pepin JL. Impaired objective daytime vigilance in obesity-hypoventilation syndrome: impact of noninvasive ventilation. Chest 2007; 131: 148-155. 
161 Lau DC, Dhillon B, Yan H, Szmitko PE, Verma S. Adipokines: molecular links between obesity and atheroslcerosis. Am J Physiol Heart Circ Physiol 2005; 288: H2031-H2041.

162 Higashiura K, Ura N, Ohata J, et al. Correlations of adiponectin level with insulin resistance and atherosclerosis in Japanese male populations. Clin Endocrinol (Oxf) 2004; 61: 753-759.
163 Hosogai N, Fukuhara A, Oshima K, et al. Adipose tissue hypoxia in obesity and its impact on adipocytokine dysregulation. Diabetes 2007; 56: 901-911.

164 Chen B, Lam KS, Wang Y, et al. Hypoxia dysregulates the production of adiponectin and plasminogen activator inhibitor-1 independent of reactive oxygen species in adipocytes. Biochem Biophys Res Commun 2006; 341: 549-556. 